\title{
Practical Use of Nitrogen Gas as a Method for Insect Control in Herbaria
}

\author{
Miriam Kritzer Van Zant ${ }^{1 *}$, Don Ugent ${ }^{2}$, and David A Lightfoot ${ }^{1 *}$ \\ 1 Department of Plant Soil and Agricultural Systems, Southern Illinois University, Carbondale, IL 62901-4415; \\ ${ }^{2}$ Southern Illinois University, Carbondale, IL 62901. In memorium.
}

Received: April 18, 2013 / Accepted: May 19, 2013

\begin{abstract}
Herbaria are libraries of dried mounted plants used for plant identification, research vouchers and teaching. Herbarium specimens are subject to damage from insects, fungi and bacteria, and must be protected by treatments that kill damaging organisms. Naphthalene, the most common chemical currently used in herbaria, is a class $C$ carcinogen and potential allergen. The aim was to develop an affordable alternative to treatment with persistent hazardous toxins for maintaining dried herbarium specimens. The new method uses ambient temperature nitrogen gas and widely available, valved, nylon, oxygen barrier bags. Nitrogen gas treatment has been shown to be less expensive than freezer storage and safer than treatment with naphthalene and other toxins. The lower hazard of nitrogen treatment compared to naphthalene offers a practical option for K-12 and institutions of higher education to initiate, reinstate or strengthen herbarium collections for teaching and/or research. This is the first report of the use of inexpensive valved oxygen barrier bags for herbarium pest control.

Keywords: Nitrogen; Herbaria; Method; Specimens; Plants; Napthalene.
\end{abstract}

*Corresp. authors: mkvzant@siu.edu and ga4082@siu.edu

\section{Introduction}

Herbarium specimens in archives are mounted on large sheets of acid-free paper, with the intention that they will last for hundreds of years (Bridson and Forman, 1989, 1998). Plant specimens are flattened to save space, dried, then sewn or glued onto paper and stacked on shelves inside tightly sealed protective cabinets. Detailed labels containing information on specimen origin and identity are attached to each sheet. Drying of specimens, at low temperatures prior to mounting on paper, is necessarily thorough. Drying reduces growth of molds and bacteria and decreases the likelihood of attack from insects. Specimens are stored in sealed cabinets except when in use. On rare occasion, invasion of storage cabinets by insects from the surrounding environment occurs, requiring treatment. However, most insects are introduced from contact with improperly treated specimens, often during storage.

Certain plant families are very susceptible to insect infestation (Jessup, 2005). Cabinets are sometimes monitored with pheromone traps. Most of these traps are specific for cigarette beetle (Lasioderma serricorne Fabricus; Jessup, 2005). Pheromone traps are especially important for large collections where not all cabinets receive regular attention. Pheromone traps should be replaced about every three months and cost about $\$ 11$ per cabinet (Herbarium Supply, 2012). Sprinkling boric acid powder every few months around cabinets is less expensive than using traps, as boric acid is not volatile and is known to kill beetles. Boric acid should not be applied directly to specimens, so is only useful to prevent infestation by crawling insects from the vicinity of cabinets. Traps may still be needed, particularly 
for monitoring susceptible plant families. Toxicity from boric acid requires ingestion (A.D.A.M., Inc., 2012; Harper et al. 2012). Diatomaceous earth is considered non-toxic to mammals (Hope, 2011 ). Diatomaceous earth works in a similar manner to boric acid. Hower, it is not as fast-acting as boric acid.

In the past, harsh chemicals containing mercury or naphthalene were applied to herbarium sheets, to improve the chances of specimens surviving attack by other organisms. Mercury is a neurotoxin, a serious human health hazard in quantities as small as 100-300 ng per kg of body weight per day (US EPA, 1997; Ziff and Ziff, 2001; Clarkson, 2002). Naphthalene displaced mercury as the standard for protection of herbarium specimens until about 20 years ago. Acute exposure to naphthalene can result in liver and neurological damage in humans (US EPA, 1999, 2004; Preuss et al., 2003). Chronic exposure may result in cataracts and retinal damage. Naphthalene has been classified by the EPA in Group C, among possible human carcinogens. The Group $C$ ranking indicates that data is still insufficient for absolute classification as a carcinogen. Students, after brief periods in herbaria where naphthalene is in use, often complain of headaches, nausea and burning eyes and skin.

Following the US EPA $(1997,1999)$ assessments, many herbaria have purchased walk-in or chest freezers (Bridson and Forman, 1989, 1998). Freezers cost more to obtain and operate than naphthalene application. Smaller herbaria, and individuals maintaining cabinets, are often unable to buy and/or maintain freezers. Freezers require more space than cabinets. Freezer malfunction allows rapid growth of mold. Freezers may cause freeze-thaw damage to specimens. The moisture in freezers can reduce the mildew protection resulting from complete drying. Freezing may not kill all insect eggs. Nonetheless, curators at the Association of Systematic Collections (Zycherman and Schrock, 1988) and Kew Herbarium (Bridson and Forman, 1989, 1998) endorse the use of either freezers or nitrogen to kill insects as an alternative to naphthalene and other harsh chemicals. Bridson and Forman (1998) recommend that nitrogen be used at temperatures above $20^{\circ} \mathrm{C}$ and that it is most effective between $30-38^{\circ} \mathrm{C}$. Further, they (Bridson and Forman, 1998) recommend treatment time for nitrogen exposure of 1 week for most insects but 1-3 weeks for wood-borer infested samples. The Hong Kong Special Administrative Region of the People's Republic of China $(2006,2012)$ has a nitrogen chamber used for curation of national treasures in the form of wooden furniture. The Hong Kong website states termites, woodborers and furniture beetles can be killed in controlled conditions of $55 \%(\mathrm{v} / \mathrm{v})$ humidity between $0.28-0.30 \%(\mathrm{v} / \mathrm{v})$ oxygen, at regulated room temperature. Nitrogen sterilizes by displacing oxygen, preventing aerobic metabolic activities (Watanabe and Morita, 1998). Hence nitrogen discourages most molds, kills most insect eggs (Morin et al., 2005), and halts the oxygen promoted breakdown of paper. Nitrogen is $80 \%(v / v)$ of the atmosphere (Raven et al., 2005). Therefore, the environmental impact of use of room temperature nitrogen for curation is generally considered to be very low. To date few specifics have been offered for controlling nitrogen for herbarium curation. We first considered existing systems for utilizing nitrogen.

Nitrogen tents have been designed for high altitude train- ing of athletes (Pedlar et al., 2005). The tents are not air tight to prevent suffocation. Therefore, altitude training tents require expensive regulators which mix air with nitrogen. Nitrogen tents used for plant research on effects of atmosphere are left open at the bottom (Holton et al., 2003). Air-tight nitrogen tents would stop plant respiration, defeating the purpose of those studies. Partially open tents require continuous free-flowing nitrogen, more costly than filling a sealed area once. Sealing an existing design would have been haphazard. Designing a new kind of tent would have required considerable time and expense.

NASA utilizes nitrogen storage systems to store moon rocks for the long term in hard shell glove boxes (Hoversten, 2000). Producing a hard shell container also requires tools, skills, time and funding. Worse, hard shell containers could implode when oxygen containing atmospheric gases are removed, prior to filling the container with nitrogen. Again expensive regulation equipment would have been needed to precisely control removal and input of gases. Hard bubble-type or room nitrogen chambers, like the one made for curation in Hong Kong, and their accompanying gas regulation equipment, are very expensive. Here we report a low cost, low hazard method, for treating samples with nitrogen using Space bags ${ }^{\circledR}$ (S.C. Johnson \& Son, Racine, Wi., USA), and simple equipment.

\section{Materials and Methods}

Space bags $®$ are sold for storing clothing and bedding. The bags contain Mylar ${ }^{\circledR}$ (DuPont Teijin Films, USA) polyester. Mylar ${ }^{\circledR}$ has oxygen barrier properties and is also found in the walls of helium balloons. Patented one-way valves on Space bags $\mathbb{B}$ provide a reliable way to remove air, including oxygen (Spacebag $\AA$ Company, 2004). Sliding air-tight seals on Space bags $₫$ operate similarly to those on Zip-lock ${ }^{\circledR}$ (S.C. Johnson \& Son, Racine, Wi., USA) sandwich bags. Space bags $\AA$ are inexpensive and available in various sizes. Manufacturers sell the bags in assorted size groupings through commercial outlets. In order to purchase bags of a single size we were required to order an assorted size grouping for about $\$ 20$ directly from the Spacebag $\AA$ Company (https://www.spacebag.com/spacebag), to establish an account. This may have changed since the company was acquired by S.C. Johnson. Four Original Jumbo 36" x 49" bags should hold the contents of a full herbarium cabinet. Three Original Jumbo bags and one Medium 18" x 22.5" bag held all of the specimens from an almost completely full standard herbarium cabinet (Fig. 1).

Equipment used included: vacuum cleaner with hose; tank containing room temperature nitrogen; standard gas regulator for the nitrogen tank; anchored position and belts for securing the nitrogen tank; tubing; boxes and box lids to protect herbarium specimens from crushing either under their own weight or due to creation of a vacuum during withdrawal of oxygen; sufficient flat surface to retain filled bags for at least one week for herbaceous material (Fig. 1). Different sized bags worked well with different sized boxes. Lids from cartons that had held packages of copy machine paper (Fig. 1), hold standard (11" x 17"; 27.9 x $43.2 \mathrm{~cm}$ ) herbarium sheets. Breaking down one side of the lid makes them the right size for holding most longer 
herbarium sheets. By staggering these box lids, weight on the lower specimens was reduced. The largest bags available when we started our trials (Original Jumbo, 36 x 49"; 91.4 x 124.5 $\mathrm{cm}$ ) held eight box lids full of specimens, paired into four slightly staggered piles. The valve on the bag used for extraction always faced upward during our study. Open boxes were used inside the bags, as they are best suited to air exchange.

Room temperature nitrogen gas was used in the experiment. It is much less expensive than liquid nitrogen and widely available. A standard vacuum cleaner with a hose (Figure 1A) was used to remove air through the bags' one-way valves. A standard gas regulator is needed for the nitrogen tank. Most institutions already have such regulators or they can be purchased for around $\$ 100.00$. Nitrogen tanks cost about $\$ 2.00$ per month per tank to keep full. There can also be a first time fee of about $\$ 75.00$ when service is started. One tank was sufficient to treat the contents of an herbarium case, with 20 of its 22 shelves filled with specimens. The amount of gas used included enough to refill bags that were improperly sealed or leaked. Bags must be monitored for potential leaks, especially for the first two days to make sure they are not deflating. The inflation or deflation of each bag provided an indicator for successful removal of air and filling with nitrogen. Sufficient table or other space was needed to leave the bags undisturbed for at least one week (Figure 1D). Air was collected from the valve positioned at the top (Figure 1), using the vacuum cleaner and hose. Tubing was used, long enough to deliver the nitrogen from the tank deeply into the back bottom of the bags (Figure 1B).

In the typical protocol, specimens were set in the bags, arranged in the open boxes with the bag's valve on top. Tubing attached to the nitrogen tank was placed as deeply as possible into the bottom back end of the bag. Seals were closed tightly against the tubing, using the provided plastic slider. Next the entire length of the seal was reinforced with the slider. Prior to inflation, the snap on valve lid was removed. The vacuum was turned on to remove enough air to cause the bag to collapse slightly around the boxes of specimens, but not enough to allow the vacuum to crush boxes or dried plant materials. Immediately after the vacuum cleaner was shut off, the nitrogen regulator valve was opened to gently inflate the bag. Care was taken to not over-fill the bag nor open the seal.

Next, at least $1 / 3$ of the gas in the bag was again removed from the top, until the bag began to collapse again against the boxes. More nitrogen was let into the bag, to re-inflate it. The process was repeated for a third time. The final step was to rapidly withdraw the tubing and immediately seal the bag. Bags that were properly sealed stayed visibly inflated. After the third filling, the valve lid was gently twisted until it snapped into position over the valve to prevent accidental leaks. If the seal opened on the bag, the whole process was repeated.
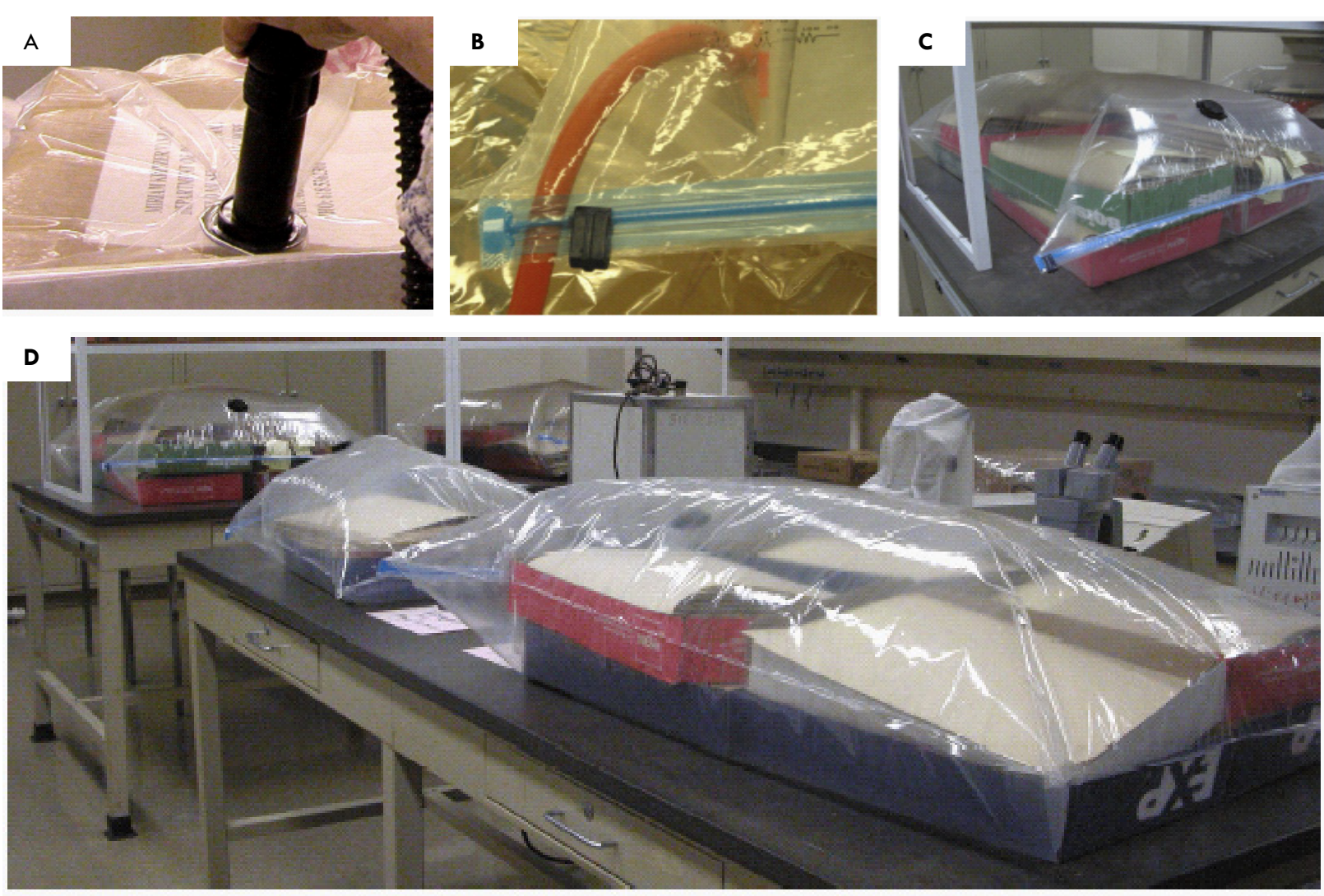

Figure 1. Use of nitrogen with valved Mylar containing bags for the preservation of herbarium specimens. Panel A shows removal of air from a bag containing boxed specimens. Panel B shows the use of tubing to deliver nitrogen gas into the bottom of the bag. Panel $C$ shows a bag inflated with nitrogen with the blue seal facing the viewer. Panel $D$ shows the contents of a standard herbarium cabinet under treatment with room temperature nitrogen. 
If moving a bag is necessary, the seal should be checked and the slider passed across the seal at the destination site. As long as the bag still appears inflated, nitrogen must remain in the bag. If any air containing oxygen were to remain in the bag, it would be pushed to the very bottom, requiring insects, bacteria and mold spores to remain at the bottom of the bag itself for the entire week to avoid asphyxiation. At the end of the treatment period, the bag should be opened facing a moving draft or ventilation system. Specimens should then immediately be placed into a clean cabinet and the door sealed.

Safety precautions must be taken when applying this method. Nitrogen is not a fire hazard but since it displaces oxygen it is an asphyxiation hazard. Though nitrogen is not a long term environmental hazard, there are some safety issues to consider for its use and release. A proper anchor and belts for the tank are necessary. Any improperly secured gas tank can become a torpedo and destroy a room, if the valve is ruptured by a fall. Securing the tank to an anchored work-bench with tank belts is essential. The gas regulator must work and be properly connected to the tank. Seals on bags can wear or pop open when gas is added so it is important to check that gas remains in the bag. Nitrogen should only be released in a ventilated area. If allowed to build up in a room, nitrogen could be hazardous to small children, pets, maintenance workers or crawlers during a fire. Nitrogen buildup could be deadly for someone who loses consciousness in the gas for a sustained period. Any plastic bag and especially an oxygen barrier bag full of nitrogen is a smothering hazard, so access by children and pets should be tightly controlled. Direct release of nitrogen into the operators face is unpleasant as it momentarily deprives lungs of air. For that reason nitrogen should not be released directly out of a window. During this study, nitrogen was mixed back into the atmosphere by releasing it into a ventilation system leading outdoors. Releasing nitrogen into a fan directed outward would give a similar result.

Moisture can build up in closed bags when they are not in use, so stored bags should be checked for molds before re-use. Though nitrogen will kill most molds, mold exposure to specimens and workers is unnecessary. Mold can be prevented by placing unused bags inside a single large bag filled with nitrogen, and/or by leaving silica dry packs in each bag.

\section{Results}

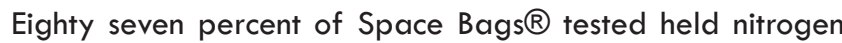
with no difficulty for one week or longer (Fig. 1). Fifty percent of the bags were still fully inflated with nitrogen at the end of three months. Full bags were carefully and successfully transported on rolling carts and even by car for short distances on several occasions. Bags that lost nitrogen, as evidenced by partial collapse visible by the second day, were refilled and stayed inflated. In these cases seals may have been jarred during filling, transport or sealing. Occasionally, bags popped open during filling, causing the operator to inhale nitrogen. Inhalation caused dry irritation to the throat, but no lasting consequences. The asphyxiation hazard is small (Watanabe and Morita, 1998) if the work is carried out in a well-ventilated area. One hundred percent of specimens treated with nitrogen in the study remained free from insects and molds for at least three years when their observation for this purpose was discontinued.

\section{Discussion and Conclusions}

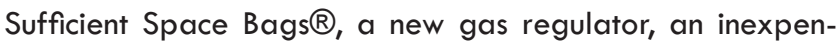
sive vacuum, tubing and sufficient nitrogen including a startup fee, to maintain the contents of one or several herbarium cabinets for one to several years, were purchased for under $\$ 400$ dollars in 2004. If a regulator and vacuum were already available and tank service established, start-up costs drop to about \$120. Yearly maintenance costs to treat specimens filling a single cabinet were between $\$ 25$ for nitrogen under a monthly contract and $\$ 125.00$ for nitrogen and replacement of all bags if needed. Pheromone traps for cigarette beetles add no more than $\$ 44$ to costs per standard cabinet per year and are optional for most teaching collections. Sufficient boric acid for periodic dusting of the floor of a typical school laboratory or classroom would cost under $\$ \mathbf{\$ 7} .00$ per year if purchased from a pharmacy. If kept dry, boric acid should keep in its container for several years. There was a one-year replacement warranty on the bags. Bags may outlast the warranty, depending on frequency of use. The same bags can be used to treat more than one cabinet and for incoming dried material, either from the field or borrowed from other institutions. There are other less expensive brands of valved oxygen barrier plastic storage bags besides Space Bag ${ }^{\circledR}$, but Mylar ${ }^{\circledR}$ contents vary among brands, and other valves may not be as effective as those patented for one way air flow. Acidity transfer from the cardboard boxes should not be an issue while the specimens are under inert conditions in nitrogen, especially as cardboard boxes are already being used to hold herbarium specimens in freezers. Boxes or lids can be lined with acid free paper if there is concern. Though we used open boxes, closed boxes may also be used inside of the bags as long as they are not air tight.

This room temperature nitrogen method for controlling invasive organisms on herbarium sheets does not result in freezethaw damage to cells. Because nitrogen halts aerobic metabolic activity, it may not prove useful for storage of propagules or pollen intended for germination. However, that remains to be tested. Freezing and thawing can alter protein structure through crystallization (Morin et al., 2005). Chemicals like naphthalene leave residues on specimens that can alter the results of pharmacognosy research and other biochemical assays. Nitrogen does not leave any residue.

Oxygen (15.999) is slightly heavier than nitrogen (14.007) according to the Periodic Table. Air contains close to $80 \%$ nitrogen and $20 \%$ oxygen. Pure oxygen would therefore be slightly heavier and pure nitrogen slightly lighter than air for the same volume. Therefore, nitrogen seeps upward, displacing the room air containing oxygen, which will sink to the bottom inside the bag. It may be better in the future to place the bags on racks with valves pointing downward. This would allow air and gas extraction from underneath, and may allow the downwardly seeping oxygen and air to be more completely extracted from the bags.

Though nitrogen gas is not available everywhere, it is avail- 
able in major cities throughout the world and can be obtained almost anywhere there is a road in developing areas. The infrastructure for transporting gas tanks exists anywhere propane is available or where acetylene torches are used. As $80 \%(v / v)$ of the atmosphere is nitrogen, there is no known long-term environmental damage from preparation, use or release. There may be environmental issues with disposal of the bags. However, there are greater problems with the disposal of freezers and their chemicals. In addition, this method may be used for short-term maintenance of material that is not dried. It would be interesting to see if some kinds of biological specimens currently maintained in costly frozen nitrogen or in formaldehyde or acetic acid (Zycherman and Schrock, 1988) would retain their usefulness if stored in room temperature nitrogen.

Others have used variations on this method for long-term specimen preservation. Fort Lee Virginia is home to the U.S. army facility for storage of archeological artifacts (Fort Lee Regional Archeological Curation Facility, 2006). The facility uses nitrogen to store artifacts for the long term. Curators there place artifacts in oxygen barrier bags, withdraw most of the oxygen containing air from the valve, fill the bags with nitrogen sometimes adding silica to keep specimens dry, and set them in a cabinet where they can be stored for up to 30 years (Jason J. Huggan,

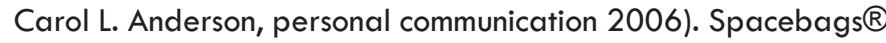
were specifically recommended by the Fort Lee curators. Treatment of herbarium material usually requires only one week of exposure to nitrogen. Researchers at the University of Hawaii have used nitrogen with dry packs in plastic bags available from herbarium supply companies for ethnobotanical specimens (Will McClatchey, personal communication 2005). However, this kind of bag is not equipped with a valve to facilitate removal of oxygen and is made of polyethylene ( $w w w . h e r b a r i u m s u p p l y . c o m)$ Polyethylene can be made to have oxygen barrier properties but this requires additional chemicals. Oxygen barrier properties were not attributed to the bags specified on the Herbarium Supply website. Preservation Equipment $\AA$ Company (2006), in the UK, sells heavier specimen preservation bags than those from Herbarium Supply Company, and also roles of film made from the same material, specified as containing nylon. Unfortunately the UK bags require special sealing machines, that cost between $£ 1,295.00$ to $£ 1,795.00$ in 2004 , and their bags still lack valves for air removal.

Spacebags $®$ cost less to buy and use, have simple to use seals and valves which allow easy access and extraction of displaced oxygen from the top with nothing more expensive than a vacuum cleaner, making them overall more adaptable for herbarium insect control. They also only take up much space when actually in use and there are no expensive costs for installation or removal as for freezers. Further, maintenance costs for nitrogen tanks are lower than monthly electric bills for freezers processing comparable numbers of specimens, and power outages are less likely to affect treatment with nitrogen. Replacement costs for the bags are much lower than maintenance costs for freezers, and bags take up less space than freezers in landfills, even when replacements are considered. There are concerns that nitrogen might cause brittleness in specimens over long periods (Will McClatchey, personal communication 2005). $\mathrm{McClatchey}$ pointed out that dry nitrogen from tanks may be preferable to the sometimes wet nitrogen made with portable units. These issues require further scrutiny for long-term storage. There may also be residual oxygen present in our system, either due to incomplete removal, or re-contamination in the moment when the tubing to deliver the nitrogen is pulled from the bags, prior to completion of sealing the opening. Only testing with insects or oxygen detectors will clarify this fully. However it is clear from our study that as bags were deflated and re-inflated, air was successfully removed and nitrogen successfully deposited into and held within the bags.

The method described here may also prove practical for protecting other insect susceptible materials such as woolen clothing, replacing chemicals and high maintenance low temperature storage in regions where storage bags alone do not provide sufficient protection.

The method described was practical for maintaining enough material to fill a single standard herbarium cabinet. It may prove less practical for large national collections as more effort is needed to organize material to fit into the bags and to fill them and release the nitrogen, than to move a box into or out of a freezer. This method may still prove useful at larger institutions for maintenance of a small number of specimens away from the main herbarium, such as in a lab or office in a distant building. The method also makes a good back up at times when need exceeds freezer space or during a break down or maintenance period for freezers.

If biologists interested in conservation do not find economically realistic, environmentally safe or at the very least safer methods to conduct research, the result will be a weakening of their disciplines. The impetus and authority for biologists to make the case for using environmentally cleaner methods to other segments of society must be prescient to the investment of time and money in finding less harmful substitutes. At the very least the method described here allows institutions to accommodate naphthalene sensitive or concerned students and provides a simple and relatively inexpensive way for small herbaria to comply with EPA recommendations concerning naphthalene in the work place.

\section{Acknowledgements}

Thanks are due to the curatorial staffs at Missouri Botanical Garden, the United States National Herbarium, Field Museum Herbarium, Fort Lee Regional Archaeological Curation Facility and to the Office of Disability Support Services at Southern Illinois University for advice and encouragement. Thanks for cooperation are due to Dr. Stephen Ebbs and the Southern Illinois University Herbarium. Dr Brian Klubek is thanked for his help. This article is dedicated to the memory of Dr. Donald Ugent, a true gentleman and scholar. 


\section{References}

A.D.A.M., Inc. (2012); (eds.) D. Zieve, and D.R. Eltz. Boric acid poisoning. U.S. National Library of Medicine website. NIH http://www.nlm.nih. gov/medlineplus/ency/article/002485.htm downloaded Mar 11 2013.

Bridson D and L Forman (1989) The Herbarium Handbook. Revised Edition, 303 pp. Royal Botanic Gardens, Kew, UK.

Bridson D and L Forman (1998) The Herbarium Handbook. 3rd edition, 334 pp. Royal Botanic Gardens, Kew, UK.

Clarkson TW (2002) The three modern faces of mercury. Environ. Health Perspect. 110: Suppl. 1:11-23.

Fort Lee Regional Archeological Curation Facility (2006) personal communication with curators Jason J. and Carol L. Anderson Website www.lee.army.mil/dpw/curation.htm. downloaded 2006.

Harper, B. J.A. Gervais, K. Buhl, and D. Stone (2012). Boric acid technical fact sheet. National Pesticide Information Center, Oregon State University Extension Services http://npic.orst.edu/factsheets/borictech.pdf downloaded Mar 112013.

Herbarium Supply Company (2006, 2013) Website http://www.herbariumsupply.com/ downloaded Jan 17 2006, and Feb 52012.

Holton MK, Lindroth RL, and Nordheim (2003) Foliar quality influence tree-herbivore-parasitoid interactions: effects of elevated $\mathrm{CO}_{2^{\prime}} \mathrm{O}_{3^{\prime}}$ and plant genotype. Oecologia 137:233-244.

Hong Kong Special Administrative Region of the People's Republic of China $(2006,2012)$ Website

http://www.lcsd.gov.hk/CE/Museum/Conservation/eng/speciality/ organics.htm. downloaded Jan 21 2006, and Feb 52012

Hope, B. 2011 . Diatomaceous earth. http://www.deq.state.or.us/er/ docs/LowerBridge/DiatomaceousEarthFactSheet.pdf DEQ (Department of Environmental Quality State of Oregon). downloaded Mar 112013.

Hoversten P. (2000) 30 Years Later, Moon Rocks Retain Their Secrets. http://www.space.com/scienceastronomy/solarsystem/moon_rock_ analysis_000522_MB_html downloaded May 52004.
Jessup WC. (2005) Integrated pest management a selected bibliography for collections care. http://palimpsest.stanford.edu/byauth/ jessup/ ipm.html downloaded May 82005.

Morin P Jr, McMullen DC, and KB Storey (2005) HIF-1 alpha involvement in low temperature and anoxia survival by a freeze tolerant insect. Mol Cell Biochem 280 (1-2): 99-106.

Pedlar C, Whyte G, Emegbo S, Stanley N, Hindmarch I, and R Godfrey (2005) Acute sleep responses in a normobaric hypoxic tent. Med Sci Sports Exerc 37: 1075-1079.

Preservation Equipment Company (2006) Website https://www2.preservationequipment.co.uk/. downloaded Jan 17, 2006.

Preuss R, J Angerer, and H Drexler (2003) Naphthalene--an environmental and occupational toxicant. Int. Arch. Occup. Environ. Health. 76 (8): 556-576.

Raven, P.H., R.F. Evert, S.E. Eichhorn (2005). Biology of plants 7th edition. W.H. Freeman and Co., NY, NY, Pp. 817.

Space Bag® Company (2004) Website https://www.spacebag.com/ spacebag downloaded 2004.

US Environmental Protection Agency (1997) Mercury report to congress office of air Quality and Standards. Washington DC: US Environmental Protection Agency.

US Environmental Protection Agency (1999) Integrated risk information system (IRIS) on naphthalene. National Center for Environmental Assessment, Office of Research and Development, Washington, DC.

US Environmental Protection Agency (2004) Technology Transfer Network Air Toxics Website 91-20-3 Naphthalene http://www.epa. gov/ttn/atw/hlthef/naphthal.html. downloaded 2004.

Watanabe T and M Morita (1998) Asphyxia due to oxygen deficiency by gaseous substances. Forensic Sci Int 96 (1): 47-59.

Ziff S and MF Ziff (2001) Dentistry without mercury. Bio-Probe, Inc. Florida, pg. 96.

Zycherman L and JR Schrock (1988) A guide to museum pest control. The Foundation of the American Institute for Conservation of Historic and Artistic Works and The Association of Systematics Collections Washington, DC. 